\title{
KREDIBILITAS DAN KEKUATAN SELEBGRAM DALAM MENINGKATKAN MINAT BELI PADA TOKO ONLINE DI INSTAGRAM
}

\section{THE CREDIBILITY OF SELEBGRAM AND POWER TO INCREASE PURCHASE INTENTION ON ONLINE STORE IN INSTAGRAM}

\author{
Muhamad Alvi Irpansyah ${ }^{1}$, Asep M. Ramdan ${ }^{2}$, R. Deni Muhammad Danial ${ }^{3}$ \\ Fakultas Ilmu Administrasi dan Humaniora, Universitas Muhammadiyah Sukabumi ${ }^{123}$ \\ irpanalvi24@gmail.com ${ }^{1}$
}

Submit, 12-02-2019 Accepted,03-04-2019 Publish, 14-04-2019

\begin{abstract}
One of the strategy that can be use in increasing consumer buying interest is by increasing the attractiveness of advertisements on Instagram, one of them is the endorsement strategy. The study aims to determine about the selebgram credibility and power to increase purchase intention on online store in instagram, as well as to see how much the influence of credibility and power of selebgram to purchase intention partially or simultaneously. The method use in this research is descriptive verificative and quantitative approaches with multiple linear regression as a data analysis technique. Research result obtained show that credibility, power and purchase intentions of online store on instagram in the good category. The magnitude of the effect of credibility and power on purchases intention on instagram by Rachel Vennya after testing simultaneously and partially have a positif and significant influence. It's amounted to 51,2\%, while the remaining $48,8 \%$ are influenced by other variables not examined in this research.
\end{abstract}

Keywords: Credibility, Power, Selebgram, Celebrity Endorsement, Purchase Intention

\begin{abstract}
ABSTRAK
Strategi yang dapat dilakukan dalam meningkatkan minat beli konsumen salah satunya dengan meningkatkan daya tarik iklan pada instagram salah satunya dengan strategi endorsement. Penelitian ini bertujuan untuk mengetahui kredibilitas dan kekuatan seorang selebgram dalam meningkatkan minat beli pada toko online di Instagram, serta untuk melihat seberapa besar pengaruh kredibilitas dan kekuatan seorang selebgram terhadap minat beli baik secara parsial maupun secara simultan. Metode yang digunakan dalam penelitian ini adalah metode deskriptif verifikatif dan pendekatan kuantitatif dengan analisis regresi linear berganda sebagai teknik analisa data. Hasil penelitian yang didapat menunjukkan bahwa kredibilitas, kekuatan dan minat pada toko online di Instagram berada pada kategori baik. Besarnya pengaruh kredibilitas dan kekuatan selebgram terhadap minat beli di Instagram oleh Rachel Vennya setelah dilakukan pengujian, secara simultan dan parsial mempunyai pengaruh yang positif dan signifikan. Total pengaruh sebesar 51,2\% sedangkan sisanya sebesar 48,8\% dipengaruhi oleh variabel lain yang tidak diteliti dalam penelitian ini.
\end{abstract}

Kata Kunci: Kredibilitas, Kekuatan, Selebgram, Celebrity Endorsement, Minat Beli 


\section{PENDAHULUAN}

Berkembangnya teknologi internet mendukung berbagai macam aplikasi media sosial yang menyebabkan ketergantungan bagi para penggunanya sehingga menyebabkan penggunaan media sosial di Indonesia semakin lama semakin bertumbuh sangat pesat, dan diperkirakan akan terus bertambah setiap tahunnya. Hal ini didukung oleh data pada ekonomi kompas yang diakses pada hari Senin, 08 Oktober 2018 merupakan hasil survey dari APJII mengungkapkan pengguna internet di Indonesia sebanyak 143,26 juta jiwa (Rakhma, 2018).

Salah satu media sosial yang banyak digunakan oleh masyarakat Indonesia adalah aplikasi untuk berbagi foto dan video yakni instagram. Instagram kini menjadi salah satu aplikasi media sosial yang paling banyak digunakan, dilansir dari data Tekno Liputan 6 yang diakses pada hari Rabu, 10 Oktober 2018 bahwa total pengguna instagram yang melakukan login sampai dengan bulan juni 2018 mencapai 1 milyar pengguna dari seluruh dunia (Jeko, 2018). Kini instagram juga telah dimanfaatkan oleh para penggunanya untuk berniaga dan menjadi seorang wirausahawan dengan membuat akun dagang pada instagram yang kini mengakibatkan banyaknya akun online store pada instagram.

Minat beli konsumen pada online store di Instagram sejatinya sangat sulit untuk diraih dan didapatkan, dikarenakan konsumen kurang memiliki keinginan untuk mengetahui produk online store pada instagram yang tidak memiliki daya tarik di mata para konsumen (Abbas dan Afshan, 2018), (Prabowo, 2014), (Pamungkas, 2014). Strategi yang dapat dilakukan dalam meningkatkan minat beli konsumen salah satunya dengan meningkatkan daya tarik iklan pada instagram salah satunya dengan strategi endorsement, dengan kata lain semakin baik dan berkualitasnya iklan yang ditampilkan oleh sebuah perusahaan semakin meningkat pula minat beli konsumen akan produk tersebut (Suharto, 2016). Sehingga mengakibatkan promosi dengan menggunakan selebriti akan memberikan stimulus untuk menimbulkan minat beli seseorang terhadap suatu produk (Apejoye, 2013), (Stephanie, dkk, 2013)

Produk yang paling sering diiklankan dengan cara endorsement dalam instagram adalah produk mode dikarenakan tren industri mode lokal dewasa ini bertumbuh dengan pesat (Gareta, 2018). Mesz_id merupakan salah satu online store yang menjual produk mode lokal pada instagram dan turut bekerjasama dalam melakukan promosi dengan cara endorsement kepada celebrity atau selebgram salah satunya adalah dengan Rachel Vennya.

Rachel Vennya dipilih karena menurut data pada brilio.net yang diakses pada hari Rabu, 10 Oktober 2018, mengungkapkan bahwa Rachel Vennya adalah selebriti instagram ternama yang telah memiliki 2.900 .000 pengikut pada akun instagramnya (Akmala, 2018) yang dapat membangun kepercayaan pengikutnya, dengan demikian konsumen produk mode lokal seringkali cenderung tidak sengaja mengalihkan persepsi mereka akan selebgram endorser terhadap produknya (Wang, dkk, 2012)

Hal - hal tersebut ditemukan oleh peneliti sebagai landasan dalam penelitian ini dengan didukung data yang telah didapatkan di lapangan. Beberapa penelitian terdahulu menunjukkan hasil bahwa kredibilitas dan power celebrity endorsement di Intagram memiliki kerterkaitan dengan minat beli. 
Kotler dan Amstrong (2018:436) menyatakan bahwa "iklan yang menggunakan narasumber (source) sebagai figur penarik perhatian merupakan salah satu cara kreatif untuk menyampaikan pesan". Pesan yang disampaikan oleh narasumber yang menarik akan lebih mudah dalam menarik perhatian konsumen. Narasumber yang digunakan dalam iklan disebut endorser (Kertamukti, 2015). Pesan dihantarkan oleh sumber yang menarik atau terkenal sehingga akan mendapatkan lebih banyak perhatian dan ingatan, karena itulah pengiklanan sering menggunakan selebriti sebagai juru bicara (Kotler \& Keller, 2016).

Kertamukti (2015) menyatakan bahwa "selebriti yang memiliki kemampuan sudah dipercaya kredibilitasnya maka selebriti tersebut akan mewakili merek yang akan diiklankan". Sehingga credibility dari seorang celebrity endorsement berpengaruh secara signifikan terhadap minat beli (Sunny dan Hani, 2014). Pada kredibilitas seorang selebriti terdapat dua indikator yakni yang pertama adalah keahlian (expertise) merupakan pengetahuan selebriti tentang produk (Kertamukti, 2015) dengan experienced (pengalaman), dan knowledgeable (pengetahuan) yang dimiliki oleh celebrity endorser sebagai item (Sunny dan Hani, 2014).

Sedangkan indikator yang kedua adalah objektivitas yang merupakan kemampuan selebriti untuk memberi keyakinan atau kepercayaan diri pada konsumen suatu produk dengan kejujuran dari celebrity endorser dan dapat dipercaya dalam menyampaikan pesan produk sebagai item (Kertamukti, 2015).

$\mathbf{H}_{1}=$ Adanya pengaruh yang positif dan signifikan antara credibility seorang selebgram terhadap minat beli konsumen.

Kertamukti (2015) menyatakan bahwa kekuatan atau power dari seorang celebrity endorsement berpengaruh secara signifikan terhadap minat beli konsumen (Sunny dan Hani, 2014; Liang, 2018). Dikarenakan menurut Kertamukti (2015) power adalah kekuatan untuk menimbulkan pengaruh dan mengikuti apa yang ditampilkan oleh komunikator.

Dalam hal ini celebrity endorser harus disesuaikan dengan image produk yang diiklankan dan kemudian personality tersebut ditransfer ke dalam merek produk yang diiklankan sehingga konsumen sadar akan keberadaan dari merek tersebut, kekuatan untuk menjadi inspirasi konsumen dan menjadi pengingat akan suatu produk (Pamungkas, 2014)

$\mathbf{H}_{2}=$ Adanya pengaruh yang positif dan signifikan antara power seorang selebgram terhadap minat beli produk mode lokal di Instagram.

Menurut Shifman dan Kanuk dalam (Wang, dkk, 2012) mendefinisikan "niat pembelian adalah perilaku transaksi yang cenderung dipamerkan oleh konsumen setelah mengevaluasi suatu produk, dan mengadopsi reaksi konsumen terhadap suatu produk untuk mengukur kemungkinan pembelian konsumen dan lebih lanjut mengatakan bahwa minat beli merupakan instruksi diri konsumen untuk melakukan pembelian atas suatu produk, melakukan perencanaan, mengambil tindakan-tindakan yang relevan seperti mengusulkan (pemrakasa), merekomendasikan (influencer), memilih, dan akhirnya mengambil keputusan untuk melakukan pembelian". 
Sedangkan Minat beli menurut Ashari dalam (Dharma dan Iskandar, 2017) merupakan rasa ketertarikan yang dialami oleh konsumen terhadap suatu produk baik barang atau jasa yang dipengaruhi oleh sikap diluar konsumen dan didalam konsumen itu sendiri. Sehingga minat beli datang ketika konsumen menerima rangsangan dari produk, sampai pada akhirnya timbul keinginan untuk membeli agar dapat memilikinya (Dharma dan Iskandar, 2017).

Untuk mengukur minat beli digunakan dimensi yang dikemukakan oleh Schiffman dan Kanuk (2004) dalam Gunawan dan Dharmayanti, (2014) indikator minat beli seorang konsumen adalah sebagai berikut: 1) ketertarikan mencari informasi yang lebih tentang produk, 2) mempertimbangkan untuk membeli, 3) keinginan untuk mengetahui produk, 4) ketertarikan untuk mencoba produk, 5) keinginan untuk memiliki produk.

Oleh karena itu kredibilitas dan kekuatan selebgram memiliki pengaruh yang kuat sehingga timbul minat beli terhadap produk yang ingin dijual oleh perusahaan (Terrence S, 2003 dalam Dharma dan Iskandar, 2017)

$\mathbf{H}_{\mathbf{4}}$ = Adanya pengaruh yang positif dan signifikan antara kredibilitas dan kekuatan seorang selebgram dalam meningkatkan minat beli konsumen.

\section{METODE PENELITIAN}

Penelitian ini dilakukan pada Mesz_id sebagai online store $\mathrm{di}$
Instagram yang melakukan strategi endorsement untuk mempromosikan produknya. Metode yang digunakan dalam penelitian ini adalah metode deskriptif dan verifikatif. Populasi dalam penelitian ini adalah pengikut (follower) akun instagram Rachel Vennya sebagai selebgram endorser produk mode lokal Mesz_id Dengan total pengikut sebanyak 2.900 .000 orang. Selanjutnya peneliti menggunakan teknik probability sampling dengan simple random sampling. Penyebaran kuesioner dilakukan kepada 400 responden. Dengan menggunakan analisis regresi linear berganda sebagai teknik analisis data. Untuk pengujian hipotesis dengan uji hipotesis secara parsial (uji t) dan uji hipotesis secara simultan (uji F).

\section{HASIL DAN PEMBAHASAN Analisis Deskriptif}

Berdasarkan data hasil analisis deskriptif credibility $\left(\mathrm{X}_{1}\right)$ mencapai nilai persentase sebesar $73,08 \%$ berada dalam kategori baik, pwer $\left(\mathrm{X}_{2}\right)$ mencapai nilai persentase sebesar 71,05\% berada dalam kategori baik, dan minat beli (Y) dengan berada pada kategori baik dengan nilai persentase $74,11 \%$.

\section{Analisis Regresi Linear Berganda}

Analisis regresi linear berganda merupakan perluasan dari regresi linear sederhana, yaitu menambah jumlah variabel bebas yang sebelumnya hanya satu variabel menjadi dua atau lebih variabel bebas atau dependent (Sanusi, 2017)

Tabel 1. Hasil Analisis Regresi Linear Berganda

\begin{tabular}{|c|c|c|c|c|c|c|c|c|}
\hline \multicolumn{9}{|c|}{ Coefficients $^{\mathrm{a}}$} \\
\hline \multirow{2}{*}{\multicolumn{2}{|c|}{ Model }} & \multicolumn{2}{|c|}{$\begin{array}{l}\text { Unstandardized } \\
\text { Coefficients }\end{array}$} & \multirow{2}{*}{$\begin{array}{c}\text { Standardized } \\
\text { Coefficients }\end{array}$} & \multirow[b]{2}{*}{$\mathbf{t}$} & \multirow[b]{2}{*}{ Sig. } & \multicolumn{2}{|c|}{ Collinearity Statistics } \\
\hline & & B & Std. Error & & & & Tolerance & VIF \\
\hline$\overline{1}$ & (Constant) & 5.447 & .739 & & 7.368 & .000 & & \\
\hline & Credibility & .279 & .040 & .324 & 6.998 & .000 & .572 & 1.749 \\
\hline
\end{tabular}




\begin{tabular}{llllllll}
\hline Power & .724 & .073 & .460 & 9.925 & .000 & .572 & 1.749 \\
\hline
\end{tabular}

a. Dependent Variable: Y (Minat Beli)

Berdasarkan tabel 1 telah didapatkan hasil pengolahan data, selanjutnya hasil tersebut dirumuskan sesuai dengan model persamaan regresi linear berganda sebagai berikut:

$$
\begin{array}{cccc} 
& \mathbf{Y}=\mathrm{a}+\mathrm{b}_{1} \mathrm{X}_{1}+\mathrm{b}_{2} \mathrm{X}_{2}+\mathrm{e} & \\
& \mathbf{Y}=5.447+0,279 \mathrm{X}_{1}+0,724 \mathrm{X}_{2}+\varepsilon \\
& & & \\
\mathrm{Y} \quad & =\text { Minat Beli } & \mathrm{X}_{2} & =\text { Power } \\
\mathrm{X}_{1} \quad & =\text { Kredibilitas } & \varepsilon & =\text { Residual }
\end{array}
$$

1. Konstantan (a) memiliki nilai sebesar 5.447 ini menunjukkan jika kredibilitas $\left(\mathrm{X}_{1}\right)$ dan power $\left(\mathrm{X}_{2}\right)$ bernilai nol maka minat beli (Y) memiliki nilai sebesar 5.447.

2. Variabel $X_{1}$ memiliki nilai koefisien regresi positif sebesar 0,279 , dapat diartikan bahwa jika variabel independen lain nilainya tetap atau tidak berubah, maka setiap kenaikan 1 poin atau $1 \%$ variabel kredibilitas akan meningkatkan minat beli sebesar 0.279. Semakin meningkat nilai $\mathrm{X}_{1}$ (kredibilitas) maka akan meningkatkan Y (minat beli).

3. Variabel $\mathrm{X}_{2}$ memiliki nilai koefisien regresi positif sebesar 0,724, dapat diartikan bahwa jika variabel independen lain nilainya tetap atau tidak berubah, maka setiap kenaikan 1 poin atau $1 \%$ variabel power akan meningkatkan minat beli sebesar 0.724. Semakin meningkat nilai $\mathrm{X}_{2}$ (power) maka akan meningkatkan $\mathrm{Y}$ (minat beli).

\begin{tabular}{|c|c|c|c|c|}
\hline \multicolumn{5}{|c|}{ Model Summary } \\
\hline Model & $\mathrm{R}$ & R Square & $\begin{array}{l}\text { Adjusted R } \\
\text { Square }\end{array}$ & $\begin{array}{l}\text { Std. Error of } \\
\text { the Estimate }\end{array}$ \\
\hline 1 & $.716^{\mathrm{a}}$ & .512 & .510 & 2.41341 \\
\hline
\end{tabular}

Koefisien Determinasi $\left(\mathbf{R}^{2}\right)$

Tabel 2. Hasil Koefisien Determinasi
Dapat dilihat bahwa angka $\mathrm{R}$ sebesar 0,716 menunjukkan adanya hubungan (korelasi) yang tinggi antara variabel dependen (Y) yaitu minat beli dengan variabel independen $\left(\mathrm{X}_{1}\right)$ kredibilitas dan $\left(\mathrm{X}_{2}\right)$ power karena berada pada rentang $0,60-0,799$ yaitu 0,716 . Untuk nilai $\mathrm{R}^{2}$ didapat sebesar 0,512 hal ini menunjukkan bahwa persentase sumbangan atau pengaruh variabel kredibilitas $\left(\mathrm{X}_{1}\right)$ dan power $\left(\mathrm{X}_{2}\right)$ terhadap minat beli (Y) dalam model regresi sebesar $51,2 \%$ sedangkan sisanya sebesar $48,8 \%$ dipengaruhi oleh variabel lain yang tidak digunakan dalam penelitian ini. Terakhir, hasil pada Adjusted $R$ Square diartikan sebagai bentuk nilai $\mathrm{R}^{2}$ yang telah disesuaikan yaitu sebesar 0,510 atau $51 \%$.

\section{Uji Hipotesis Secara Simultan (F-

\begin{tabular}{|c|c|c|c|c|c|}
\hline \multicolumn{6}{|c|}{ ANOVA $^{\mathrm{a}}$} \\
\hline Model & $\begin{array}{l}\text { Sum of } \\
\text { Squares }\end{array}$ & df & $\begin{array}{l}\text { Mean } \\
\text { Square }\end{array}$ & $\mathrm{F}$ & Sig. \\
\hline Regression & 2429.202 & 2 & 1214.601 & 208.532 & $.000 \mathrm{~b}$ \\
\hline 1 Residual & 2312.339 & 397 & 5.825 & & \\
\hline Total & 4741.541 & 399 & & & \\
\hline \multicolumn{6}{|c|}{ a. Dependent Variable: Minat_Beli } \\
\hline b. Predictors: & istant), Powe & Credil & & & \\
\hline
\end{tabular} Test)}

\section{Tabel 3. Hasil Uji F}

Setelah uji hipotesis maka pada penelitian ini didapatkan $F_{\text {hitung }}$ sebesar 208.532 sehingga dapat disimpulkan bahwa $F_{\text {hitung }}$ lebih besar dari $F_{\text {tabel, }}$ yakni $208.532>3.87$. Hal ini menunjukkan bahwa hipotesis diterima, dengan kata lain kredibilitas dan power mempunyai pengaruh signifikan terhadap minat beli pada toko online di Instagram. Selain $F_{\text {hitung, dari tabel } 4}$ juga dapat dilihat nilai regresi memiliki tingkat signifikansi 0.000 , nilai ini lebih kecil dari 0.05 atau milai Sig $<\alpha$. Dapat disimpulkan bahwa hipotesis penelitian 
yang menyatakan "Adanya pengaruh yang positif dan signifikan antara kredibilitas dan power seorang selebgram dalam meningkatkan minat beli konsumen" diterima.

Uji Hipotesis Secara Parsial (T-Test)

Tabel 4. Hasil Uji T

\begin{tabular}{|c|c|c|c|c|c|c|c|}
\hline \multicolumn{8}{|c|}{ Coefficientsa } \\
\hline \multirow[b]{2}{*}{ Model } & \multicolumn{2}{|c|}{$\begin{array}{c}\text { Unstandardized } \\
\text { Coefficients }\end{array}$} & \multirow{2}{*}{$\begin{array}{c}\text { Standardized } \\
\text { Coefficients } \\
\text { Beta } \\
\end{array}$} & \multirow[b]{2}{*}{$\mathrm{t}$} & \multirow[b]{2}{*}{ Sig. } & \multicolumn{2}{|c|}{ Collinearity Statistics } \\
\hline & $\mathrm{B}$ & Std. Error & & & & Tolerance & VIF \\
\hline (Constant) & 5.447 & .739 & & 7.368 & .000 & & \\
\hline Credibility & .279 & .040 & .324 & 6.998 & .000 & .572 & 1.749 \\
\hline Power & .724 & .073 & .460 & 9.925 & .000 & .572 & 1.749 \\
\hline
\end{tabular}

a. Dependent Variable: Minat_Beli

Berdasarkan tabel 4 dapat ditarik kesimpulan bahwa variabel kredibilitas $\left(\mathrm{X}_{1}\right)$ memiliki $\mathrm{t}_{\text {hitung }}$ sebesar 6.998 dan nilai signifikansi sebesar 0.000 maka hipotesis diterima karena $t_{\text {hitung }}>t_{\text {tabel }}$ yakni $6.998>1.65$ dengan $\mathrm{Sig}<0.05$ yakni $0.000<0.05$. Variabel power $\left(\mathrm{X}_{2}\right)$ memiliki $t_{\text {hitung }}$ sebesar 9.925 dan nilai signifikansi sebesar 0.00 maka hipotesis diterima karena $t_{\text {hitung }}>t_{\text {tabel }}$ yakni 9.925 $>1.65$ dengan $\mathrm{Sig}<0.05$ yakni $0.00<$ 0.05 .

Sehingga dari hasil uji $\mathrm{t}$ dapat diketahui bahwa secara parsial kredibilitas selebgram $\left(\mathrm{X}_{1}\right)$ dan power selebgram $\left(\mathrm{X}_{2}\right)$ mempunyai pengaruh signifikan terhadap minat beli (Y) pada toko online di Instagram. Hasil penelitian ini sejalan dengan penelitian yang dilakukan oleh Apejoye (2013) dan Stephanie, dkk (2013). Semakin tinggi kredibilitas selegram dan power selebgram maka semakin tinggi pula minat seseorang membeli produk atau jasa endorse dari selebgram tersebut.

\section{PENUTUP}

\section{Kesimpulan}

Berdasarkan analisis yang telah dilakukan, peneliti menemukan beberapa kesimpulan untuk menjawab pertanyaan pada penelitian ini. Dengan teknik analisis regresi linear berganda diketahui bahwa total pengaruh $\mathrm{X}_{1}$ dan $\mathrm{X}_{2}$ baik secara langsung maupun tidak langsung terhadap $\mathrm{Y}$ adalah sebesar 0,512 atau $51,2 \%$ dan epsilon atau sisa pengaruh independen lainnya yang berperngaruh terhadap minat beli (Y) namun tidak diteliti adalah sebesar 0,488 atau $48,8 \%$.

Selanjutnya setelah dilakukan uji hipotesis secara parsial dan simultan didapatkan hasil penelitian yang menunjukkan bahwa terdapat pengaruh yang signifikan dan positif secara parsial antara kredibilitas $\left(\mathrm{X}_{1}\right)$ dan power $\left(\mathrm{X}_{2}\right)$ terhadap minat beli $(\mathrm{Y})$ pada toko online di Instagram. Serta terdapat pengaruh yang signifikan dan positif secara simultan antara kredibilitas $\left(\mathrm{X}_{1}\right)$ dan power $\left(\mathrm{X}_{2}\right)$ selebgram terhadap minat beli (Y) pada toko online di Instagram.

\section{Saran}

Ada beberapa hal yang harus diperhatikan tentang kredibilitas dan power selebgram dalam meningkatkan minat beli pada toko online di Instargam, antara lain: (1) Pada credibility, hendaknya Rachel Vennya dapat menyaring atau lebih selektif dalam memilih produk untuk diiklankan 
(endorsement) agar kredibilitasnya meningkat sebagai endorser. (2) Dalam power, hendaknya seorang selebgram memiliki citra yang baik sehingga citra dari produk yang diiklankan akan berbanding lurus dengan citra yang dimilikinya serta seorang selebgram harus selalu menjadi inspirasi para pengikutnya (followers) dalam mengenakan produk mode lokal.

Untuk penelitian yang akan datang peneliti menyarankan antara lain untuk: (1) Menggunakan subvariabel lain yang dapat dijadikan sebagai alat ukur celebrity endorsement pada instagram agar hasil yang ditemukan lebih maksimal. (2) Memilih media lainnya yang belum banyak diteliti agar dapat menjadi penelitian baru bagi keilmuan pemasaran.

\section{DAFTAR PUSTAKA}

Abbas, A., \& Afshan, G. (2018). The Effect of Celebrity Endorsement on Customer Purchase Intention: A Comparative Study The Effect of Celebrity Endorsement on Customer Purchase Intention: A Comparative Study. Pakistan: University of Faisalabad.

Akmala, N. (2018). Rachel dan Niko memang dikenal sebagai pasangan muda yang punya gaya hidup mewah. Retrieved from https://www.brilio.net/selebritis/taj ir-melintir-ini-5-sumber-kekayaanrachel-vennya-180530q.html

Apejoye, A. (2013). Influence Of Celebrity Endorsement of Advertisement On Students' Purchase Intention. Nigeria: Abdu Gusau Polytecnic.

Dharma, K. N. A., \& Iskandar, D. (2017). Pengaruh Celebrity Endorser Jkt48 Terhadap Minat Beli Konsumen Im3 Play (studi
Kasus Pada Pengunjung Teater Jkt48 Periode 21 Februari 2016). Bandung: Telkom University.

Djuniadi, Afiffudin, M., \& Lestari, W. (2016). Statistik Inferensial: Teori, Aplikasi Dan Latihan Soal Dengan SPSS (1st ed.). Semarang: Universitas Negeri Semarang.

Gareta, S. P. (2018). Ini kontribusi industri kreatif di perekonomian Indonesia. Retrieved from https://www.antaranews.com/berit a/511673/ini-kontribusi-industrikreatif-di-perekonomian-indonesia

Gunawan, F. A., \& Dharmayanti, D. (2014). Analisis Pengaruh Iklan Televisi dan Endorser Terhadap Purchases Intention Pond's Men dengan Brand Awareness sebagai Variabel Intervening. Surabaya: Universitas Kristen Petra.

Heryanto, I., dan Triwibowo, T. (2018). Path Analysis Menggunakan SPSS dan Excel. Bandung: Informatika.

Indrawati. (2015). Metode Penelitian Manajemen Dan Bisnis.

Konvergensi Teknologi Komunikasi Dan Informasi. Bandung: PT Refika Aditama.

Jeko. (2018). Instagram Kantongi 1 Miliar Pengguna di Seluruh Dunia. Retrieved from https://www.liputan6.com/tekno/re ad/3564956/instagram-kantongi-1miliar-pengguna-di-seluruh-dunia

Kertamukti, R. (2015). Strategi Kreatif Dalam Periklanan. depok: PT Raja Grafindo Persanda.

Khan, K., Rukhsar, A., \& Shoaib, M. (2016). Influence of Celebrity Endorsement on Consumer Purchase Intention. Pakistan: Jinnah University For Woman.

Kotler, P., \& Amstrong, G. (2018). Principles Of Marketing. England: Pearson Edition Limited.

Kotler, P., \& Keller, K. L. (2016). 
Marketing Management 15th Edition. England: Pearson Edition Limited.

Kurniawan, A. (2014). Metode Riset Untuk Ekonomi \& Bisnis. Bandung: Alfabeta.

Liang, H.-L. (2018). Influence of multiple endorser-product patterns on purchase intention An interpretation of elaboration. Taiwan: R.O.C Air Force Institute Of Thecnology.

Pamungkas, A. (2014). Pengaruh kualitas produk, daya tarik iklan, dan Celebrity Endorser Terhadap Minat Beli (Studi Pada Handphone Merek Nokia). Yogyakarta: Universitas Negeri Yogyakarta.

Prabowo, Y. W. (2014). Pengaruh Celebrity Endorser Terhadap Minat Beli (Survei Pada Pengunjung 3second Store Di Jalan Soekarno Hatta Malang). Malang: Universitas Brawijaya.

Riduwan. (2016). Dasar-Dasar Statistika. Bandung: Alfabeta.

Sanusi, A. (2017). Metodologi Penelitian Bisnis. Jakarta: Salemba Empat.

Stephanie, E., Rumambi, L. J., \& Sondang, Y. (2013). Analisa Pengaruh Rio Dewanto dan Donita Sebagai Celebrity Endorser
Terhadap Minat Beli Rroduk Axe Anarchy Dengan Daya Tarik Iklan dan Efek Iklan Sebagai Variabel Intervening. Surabaya: Universitas Kristen Petra.

Sugiyono. (2017). Metode Penelitian Pendidikan Pendekatan Kuantitatif, Kualitatif dan $R \& D$. Bandung: Alfabeta.

Suharto, C. A. A. (2016). Analisis Pengaruh Citra Merek, Harga, Dan Daya Tarik Iklan Terhadap Minat Beli Konsumen Pada PT. Remaja Jaya Mobilindo Manado. Manado: Universitas Sam Ratulangi.

Sunny, S., \& Hani, S. (2014). Pengaruh Celebrity Endorsement Terhadap Minat Beli Mie Sedaap (Studi Kasus Pada Iklan Mie Sedaap dengan Celebrity Endorser Edwin Lau). Salatiga: Universitas Kristen Satya Wacana.

Umar, H. (2014). Metode Penelitian Untuk Skripsi dan Tesis Bisnis. Jakarta: PT Raja Grafindo Persanda.

Wang, J., Cheng, Y., \& Chu, Y. (2012). Effect of Celebrity Endorsements on Consumer Purchase Intentions : Advertising Effect and Advertising Appeal as Mediators. Taiwan Shu$\mathrm{Tu}$

University. 